\title{
Experimental Study of the Mechanism of Seizure Induction: Changes in the Concentrations of Excitatory Amino Acids in the Epileptic Focus of the Cat Amygdaloid Kindling Model
}

\author{
Hiroyuki NAKASE, Takaoki TADA*, Hiroshi HASHIMOTO, \\ Shinichiro KUROKAWA, Hidehiro HIRABAYASHI, Tohru HoSHIDA, \\ Toshisuke SAKAKI, and Hideyuki OHNISHI** \\ Department of Neurosurgery, Nara Medical University, Kashihara, Nara; \\ ${ }^{*}$ Department of Neurosurgery, National Nara Hospital, Nara; \\ ${ }^{* *}$ Department of Neurosurgery, Osaka Neurological Institute, Toyonaka, Osaka
}

\begin{abstract}
L-glutamate (Glu) and L-aspartate (Asp) are two major excitatory amino acids that may be involved in seizure susceptibility and seizure induction. The concentrations of Glu and Asp were measured by microdialysis in the epileptic focus in a cat amygdaloid kindling model. Sequential changes in Glu and Asp (before, during, and after seizure) were measured in the partial seizure (S4) and generalized seizure (S6) groups. By stimulation at and $50 \mu \mathrm{A}$ below the partial seizure-triggering threshold in the $\mathrm{S} 4$ group and the generalized seizure-triggering threshold in the S6 group, Glu was released from the epileptic focus in the S4 group, and both Glu and Asp were released in the S6 group after seizure and stimulation (below threshold), and the amount of Glu and/or Asp release determined seizure induction. Excitatory amino acids may be the trigger of seizure induction in the cat amygdaloid kindling model.
\end{abstract}

Key words: seizure induction, excitatory amino acid, kindling

\section{Introduction}

Excitatory amino acids are important in the susceptibility and induction of epileptic seizure, ${ }^{1,2.4-9,}$ but the mechanism of action is still unknown. Increased release of endogenous glutamic acid (Glu) and aspartic acid (Asp) occurs in kindled tissue when stimulated in vitro. ${ }^{4)}$ Increased intracerebroventricular concentrations of Glu are associated with the development of amygdaloid-kindled seizures, and the intracerebroventricular administration of 2amino-7-phosphoheptanoic acid (a specific Asp antagonist) or the Asp analog N-methyl-D-aspartate suppress amygdaloid-kindled seizures. ${ }^{10)}$ Kindling is a chronic animal model of epilepsy, characterized by a progressive increase in the response to the same regularly applied electrical and/or chemical stimula-

Received August 30, 1993; Accepted March 30, 1994 tion. ${ }^{15}$ Although well characterized phenomenologically, the mechanisms of its seizure susceptibility and induction are generally unknown.

We previously found that increased contents of excitatory amino acids in the brain and cerebrospinal fluid (CSF) are related to seizure susceptibility and induction, and concluded that Glu is involved in seizure induction in the cat amygdaloid kindling model. ${ }^{97}$ However, more specific assessment of the participation of excitatory amino acids during seizure induction requires measurement of changes in the concentrations of these substances in the epileptic focus during seizures.

The microdialysis system ${ }^{(4)}$ is an advanced highperformance liquid chromatography (HPLC) system which can accurately analyze sequential samples, obtained by perfusing a probe, in the low microliter range with a good time resolution. This study examined sequential changes in the concentration of the excitatory amino acids, Glu and Asp, at the epileptic 
focus in the cat amygdaloid kindling model using the microdialysis system.

\section{Materials and Methods}

Twenty cross-bred adult cats weighing $2.5-4.0 \mathrm{~kg}$ were used in these experiments.

Surface and depth electrodes and a ground electrode were implanted in the skulls of all cats using stereotactic techniques under $1.0 \%$ halothane anesthesia. An insulated bipolar twisted stainless wire electrode $(1.0 \mathrm{~mm}$ diameter) was aimed at the right lateral amygdaloid nucleus $(11.0 \mathrm{~mm}$ anterior, $10.5 \mathrm{~mm}$ laterally to the right, $6.0 \mathrm{~mm}$ deep from the standard point located $10 \mathrm{~mm}$ above the interaural point) according to the atlas of Jasper and AjmoneMarson. ${ }^{3)}$ The electrode tips were then spread 1.0 $\mathrm{mm}$. All connections were soldered to miniature plugs which were fixed to the skull with acrylic dental cement. The locations of the electrodes were verified postmortem."

Three days after surgery, the afterdischarge thresholds were determined and the animals were then kindled once daily at a current intensity (2-sec pulses of $60 \mathrm{~Hz}$ consisting of a charge-balanced biphasic constant current of $200 \mu \mathrm{A}$ ) sufficient to produce afterdischarges using an electrical stimulator (SEN-7203; Nihon Kohden, Tokyo). Two groups of cats were prepared: a partial seizure group (S4) which had just attained stage 4 seizure (contralateral head turning with tonic extension of the contralateral forepaw following stage 3 seizure), and a generalized seizure group (S6) which had attained stage 6 seizure (generalized convulsive seizure) according to the criteria of Wada and Sato. ${ }^{15)}$ The S6 group was the fully kindled group and required five consecutive $S 6$ seizures. Development and manifestations of induced seizure, electroencephalographic (EEG) findings, and the locations of electrodes in our cat amygdaloid kindling model have already been reported in detail." Stage 4 seizure required an average of $7.2 \pm 1.1$ (mean $\pm \mathrm{SD}$ ) days to attain and stage 6 required $19.4 \pm 2.2$ days.

Experiment 1: This experiment used an $\mathrm{S} 4$ group ( 5 cats) and an $\mathbf{S 6}$ group (5 cats). The partial seizuretriggering threshold (PST) in the S4 group and the generalized seizure-triggering threshold (GST) in the S6 group were determined. Under $1.0 \%$ halothane anesthesia, a microdialysis probe (CMA/10; Carnegie Medicine, Stockholm, Sweden) (dialyzing membrane $1.0 \mathrm{~mm}$ in length and $0.5 \mathrm{~mm}$ in diameter) was implanted stereotactically into the kindled focus in the right amygdala with a posterior inclination of $30^{\circ}$. Sixty minutes after implantation and 15 minutes after stopping the halothane anesthesia, the presence of a normal EEG was confirmed without effects of anesthesia. The Glu and Asp concentrations in the extracellular fluid were then measured at 5 -minute intervals from 15 minutes before to 30 minutes after seizure induction.

Samples were obtained by perfusing the probe with artificial $\mathrm{CSF}\left(\mathrm{Na}^{+} 143 \mathrm{mEq} / \mathrm{l}, \mathrm{Ca}^{2+} 2.4 \mathrm{mEq} / \mathrm{l}\right.$, $\mathrm{Mg}^{2+} 2.4 \mathrm{mEq} / 1, \mathrm{Cl}^{-} 112.0 \mathrm{mEq} / 1, \mathrm{HCO}_{3}^{-} 23.0$ $\mathrm{mEq} / \mathrm{l}, \quad \mathrm{PO}_{4}{ }^{2-} 1.0 \mathrm{mEq} / 1, \mathrm{SO}_{4}{ }^{2-} 0.7 \mathrm{mEq} / \mathrm{l}$, and glucose $60 \mathrm{mg} / \mathrm{dl}$, pH 7.4) (MOS-4; Shimizu, Shizuoka) at a flow rate of $2 \mu \mathrm{l} / \mathrm{min}$ for 5 minutes using a microinjection pump (CMA/100; Carnegie Medicine). The mean concentration in the total $10-\mu 1$ sample was then measured using HPLC (BAS 400 liquid chromatograph; Bioanalytical Systems, West Lafayette, Ind., U.S.A.).

The body temperature was kept at approximately $37^{\circ} \mathrm{C}$ with an animal temperature control system (CMA/150; Carnegie Medicine) and an animal heating pad.

Experiment 2: This experiment also used $\mathrm{S} 4$ and S6 groups (5 cats each). The Glu and Asp levels were measured as in Experiment 1 but stimulation used a current $50 \mu \mathrm{A}$ lower than the PST or GST.

Statistical analysis: Data are expressed as the mean value $\pm S D$. Results were compared by nonpaired Student's t-test. Values of $p$ less than 0.05 were considered statistically significant.

\section{Results}

Experiment 1: The pre-seizure $(0.39 \pm 0.06 \mathrm{pmol} /$ $5 \mathrm{~min})$ and post-seizure $(0.58 \pm 0.20)$ Asp concentrations showed no significant difference in the S4 group, but the Asp concentration rose transiently in the post-seizure period $(1.05 \pm 0.20)$ compared to the pre-seizure level $(0.40 \pm 0.07)$ in the S6 group. The Glu concentration increased transiently but significantly in both the $\mathrm{S} 4(0.71 \pm 0.10$ to $2.1 \pm$ $0.50)$ and $S 6$ groups $(0.70 \pm 0.12$ to $3.60 \pm 0.86)$ (Fig. 1).

Experiment 2: The PST was $151.2 \pm 18.8 \mu \mathrm{A}$ for $\mathrm{S} 4$ cats and the GST was $112.3 \pm 19.6 \mu \mathrm{A}$ for S6 cats. Stimulation at $50 \mu \mathrm{A}$ lower than the PST or GST caused no seizures to be induced. The Asp concentration in the 66 group increased transiently poststimulation $(0.76 \pm 0.09)$ compared to pre-stimulation $(0.40 \pm 0.01)$. The Glu concentration increased transiently but significantly in both the S4 $(0.71 \pm$ 0.03 to $1.45 \pm 0.35)$ and $S 6$ groups $(0.71 \pm 0.02$ to $1.73 \pm 0.30$ ) (Fig. 2).

The increase in Asp concentration caused by stimulation at the GST in the S6 group (threshold in 

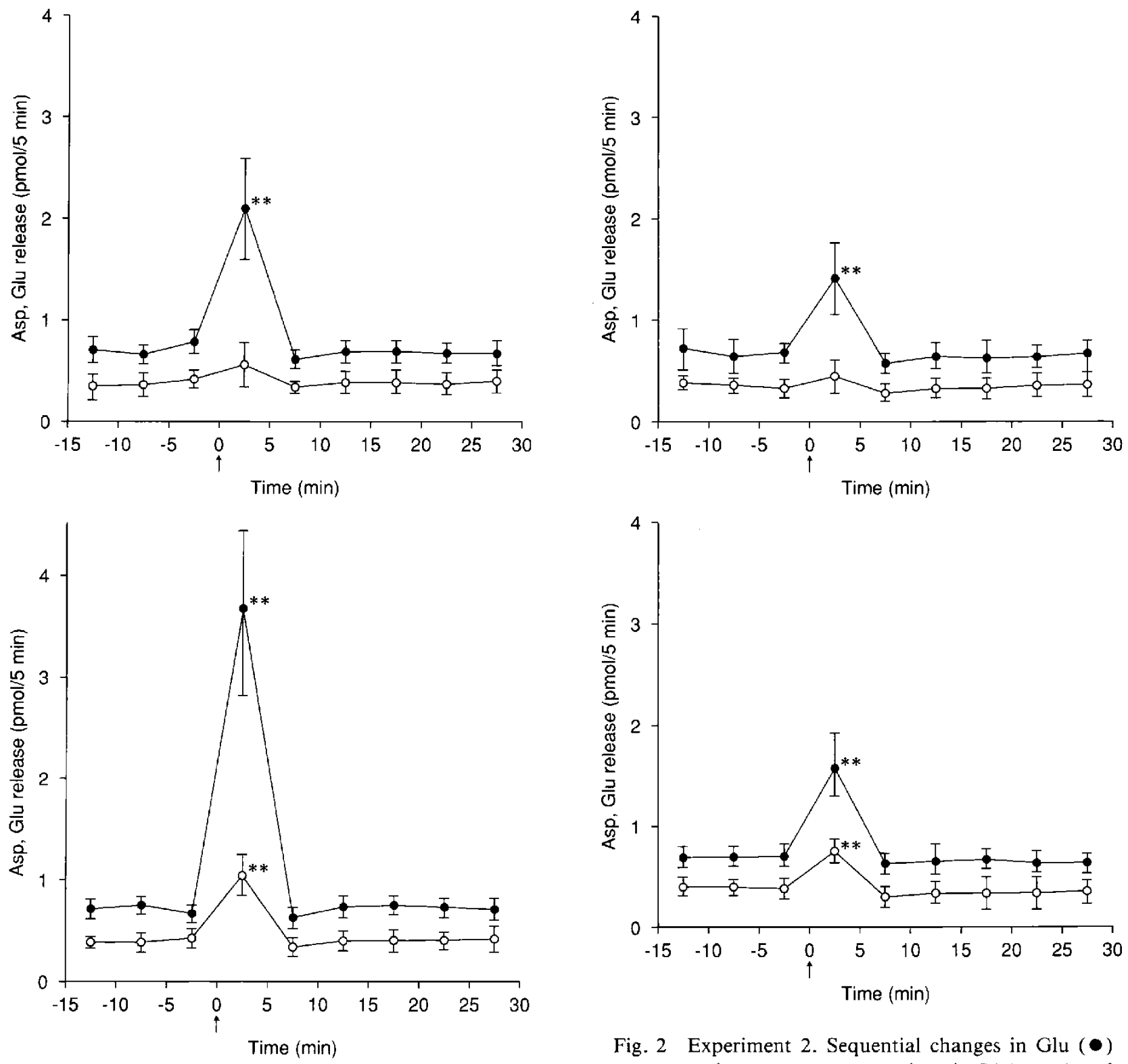

Fig. 1 Experiment 1. Sequential changes in Glu (•) and Asp (O) concentrations in extracellular fluid at the epileptic focus in S4 (upper) and S6 (lower) cats. upper: Glu concentration increased transiently and significantly just after seizure. Asp did not change significantly. lower: Asp and Glu increased transiently and significantly just after seizure. ${ }^{* *} \mathrm{p}<0.01 \mathrm{vs}$. pre-seizure, $n=5$. Arrow indicates stimulation.

Experiment 1) was significantly higher than that caused by stimulation below the GST (below threshold in Experiment 2). The increases in Glu concentration caused by stimulation at the PST in the S4

Fig. 2 Experiment 2. Sequential changes in Glu (•) and Asp (O) concentrations in S4 (upper) and S6 (lower) cats. upper: Glu concentration increased significantly but Asp concentration did not change as in Experiment 1. lower: Both Asp and Glu concentrations increased significantly as in Experiment $1 .{ }^{* *} \mathrm{p}<0.01$ vs. pre-stimulation, $n=5$. Arrow indicates stimulation.

and GST in the S6 groups (threshold in Experiment 1) were significantly higher than that caused by stimulation below the PST and GST (below threshold in Experiment 2) (Table 1). 
Table 1 Increases in Asp and Glu concentrations

\begin{tabular}{|c|c|c|c|c|}
\hline & \multicolumn{2}{|c|}{ Asp (pmol/5 min) } & \multicolumn{2}{|c|}{ Glu (pmol/5 min) } \\
\hline & $\mathrm{S} 4$ & S6 & $\$ 4$ & S6 \\
\hline Below threshold & $0.41 \pm 0.02$ & $0.76 \pm 0.09$ & $1.45 \pm 0.35$ & $1.73 \pm 0.30$ \\
\hline Threshold & $0.58 \pm 0.20$ & $1.05 \pm 0.20^{*}$ & $2.10 \pm 0.50^{*}$ & $3.60 \pm 0.86^{* *}$ \\
\hline
\end{tabular}

${ }^{*} \mathrm{p}<0.05,{ }^{* *} \mathrm{p}<0.01$ vs. values by stimulation below threshold.

\section{Discussion}

Our present study of the sequential changes in Glu and Asp in the epileptic focus during seizure induction using a microdialysis system showed that Glu is released from the epileptic focus after partial seizure and stimulation (below threshold) in stage 4 seizure cats, while both Glu and Asp are released after generalized seizure and stimulation (below threshold) in stage 6 seizure cats, and that the amount of Glu and/or Asp release determines whether seizure induction occurs. Therefore, these excitatory amino acids may be the trigger for seizure induction in cats with amygdaloid kindling.

Intracerebral injection of Glu or Asp is significantly less potent than a comparable combined injection of both Glu and Asp in a molar ratio of $1: 3 .^{11}$ However, in our experiment the release ratio of Glu and Asp was 3.6:1 in partial seizure and 3.4:1 in generalized seizure. Recently, L-glutamic acid diethyl ester, a specific quisqualate receptor antagonist, was found to suppress amygdaloid-kindled convulsions. ${ }^{13)}$ As Glu has the highest affinity to quisqualate receptors of the excitatory amino acids, these findings suggest that Glu is very important in amygdaloid-kindled seizure induction. However, no changes in Glu receptors in kindled brain have been reported. ${ }^{(2)}$

Mori and Wada ${ }^{5,6)}$ have reported that a striking bidirectional transfer of seizure susceptibility occurs at the same amygdaloid site and that transhemispheric transfer occurs between Glu/Asp stimulation and electrical kindling, with Glu/Aspkindled seizure susceptibility persisting after 30 days. They concluded that the Glu/Asp system participates in the development and persistence of increased seizure susceptibility induced by amygdaloid kindling. We demonstrated an increase in Glu and/ or Asp concentrations by stimulations below the PST or GST, showing the increase is a result of both convulsion and stimulation. These findings suggest that the release of excitatory amino acids may be involved in seizure susceptibility.
The excess release of excitatory amino acids, Glu and Asp, following electric stimulation may be the trigger for seizure induction in the cat amygdaloid kindling model.

\section{References}

1) Fabisiak JP, Schmark WS: Cerebral free amino acids in the amygdaloid kindling model of epilepsy. Neuropharmacology 21: 179-182, 1982

2) Iadorola MJ, Nicoletti F, Rananjo JR, Putnam F, Costa E: Kindling enhances the stimulation of inositol phospholipid hydrolysis elicited by iboteic acid in the rat hippocampal slices. Brain Res 374: 174178,1986

3) Jasper HH, Ajmone-Marson C: A Stereotaxic Atlas of the Diencephalon of the Cat. Ottawa, The National Research of Canada, 1954, pp 23-28

4) Leach MJ, Marden CM, Miller AA, O’Donnell RA, Weston SB: Changes in cortical amino acids during electrical kindling in rat. Neuropharmacology 24: 937-940, 1985

5) Mori N, Wada JA: Bidirectional transfer between kindling induced by excitatory amino acids and electrical stimulation. Brain Res 425: 45-48, 1987

6) Mori N, Wada JA: Bidirectional transhemispheric interaction between amygdaloid kindling induced by excitatory amino acids and electrical stimulation. Epilepsia 30: 271-275, 1989

7) Nakase H: Changes of neuropeptide contents, immunoreactive somatostatin and thyrotropin-releasing hormone (TRH), in cerebrospinal fluid and brain in the development of cat amygdaloid kindling. Nara Igaku Zasshi 41: 82-98, 1990 (in Japanese)

8) Nakase H, Tada T, Eguchi T, Hirabayashi $H$, Morimoto T, Sakaki T: Sequential changes in content of excitatory amino acids in the epileptic focus during seizure. No To Shinkei 43: 451-454, 1991 (in Japanese)

9) Nakase H, Tada T, Eguchi T, Hirabayashi H, Sakaki $\mathrm{T}$, Enoki $\mathrm{Y}$ : Changes in content of excitatory amino acids in the brain and cerebrospinal fluid. No To Shinkei 42: 971-977, 1990 (in Japanese)

10) Peterson DW, Collins JF, Bradford HF: The kindled amygdala model of epilepsy: Anticonvulsant action of amino acid antagonists. Brain Res 275: 169-172, 
1983

11) Sato $T$, Mori $N$, Kumashiro $H$ : A new model of epileptic seizure utilizing the additive excitatory activity by combination of two excitatory amino acids. Folia Psychiatr Neurol Jpn 39: 431-432, 1985

12) Savage DD, Werling LL, Nalder JV, McNamara JO: Selective and reversible increase in the number of quisqualate-sensitive glutamate binding sites on hippocampal membranes after bundle kindling. Brain Res 307: 332-335, 1984

13) Tsunoda $T$, Matsumoto $S$, Ogata $S$, Sato $T$, Mori $N$, Kumashiro H: Suppression of glutamic acid diethyl ester to amygdaloid kindled seizure, in: Proceedings of the 24th Annual Meeting of the Japan Epilepsy Society. 1990, p 130
14) Ungerstedt $U$, Herrera-Marschitz $M$, Jungnelius $U$, Stahle L, Tossmann U, Zetterstrom T: Dopamine synaptic mechanisms reflected in studies combining behavioral recordings and brain dialysis. Advances in Dopamine Research 37: 219-231, 1982

15) Wada JA, Sato $M$ : Generalized convulsive seizures induced by daily electrical stimulation of the amygdala in cat: Correlative electrographic and behavioral features. Neurology (Minneap) 24: 565-574, 1974

Address reprint requests to: H. Nakase, M.D., Department of Neurosurgery, Nara Medical University, 840 Shijo-cho, Kashihara, Nara 634, Japan. 